\title{
“ESTRANHAS MAS IRMÃs": REVISITANDO A QUESTÃO DAS DUAS CULTURAS
}

\author{
Carlos Fiolhais
}

\begin{abstract}
RESUMO
É discutida a relação entre Arte e Ciência. É indicada a necessidade da construção de pontes entre a cultura artística e a cultura científica, as quais cresceram separadas, embora os assíduos contactos entre elas tenham conduzido sempre a enriquecimento mútuo. Cotejam-se afirmações de Charles Snow e de Jacob Bronowski nos anos 50 do século passado com as do português António Lobo Vilela, um intelectual proscrito do Estado Novo muito atento à cultura científica que escreveu um livro intitulado "Ciência e Poesia". Tendo presente a história deste debate, sustenta-se o aprofundamento das referidas pontes, de modo a concretizar a união da cultura artística e da cultura científica.
\end{abstract}

PALAVRAS-ChaVe

Ciência; arte; cultura; poesia; comunicação; linguagem

Em 7 de Maio de 1959 o físico-químico, romancista, político e intelectual público Charles Percy Snow inglês (1905-1980), mais conhecido pelo nome abreviado C. P. Snow, proferiu na Universidade de Cambridge, no Reino Unido, uma famosa conferência no quadro das Rede Lectures (iniciadas em 1706), intitulada "As Duas Culturas". Essa palestra está contida no livro com o mesmo título que contém o texto da conferência e que tem sido, em todo o mundo editado, reeditado, traduzido e comentado (Snow, 1963).

Em Portugal saiu uma edição desse livro nas Publicações Dom Quixote em 1965. Foi um dos primeiros livros do prelo desta editora, dirigida por Snu Abecassis, uma vez que foi publicado em Agosto desse ano, após o início da sua atividade editorial em Abril. Em 1996, saiu uma outra edição na Presença. É desta última, com tradução de Miguel Serras Pereira, que retiro a expressiva defesa que Snow faz do seu ponto principal, que é a manifesta limitação do que apelida "cultura tradicional". A citação é um pouco longa, mas vale a pena deixá-la aqui pois ela encerra o cerne da polémica desencadeada pela conferência:

As pessoas são também limitadas - e talvez mais gravemente, uma vez que mostram um grande orgulho nas suas limitações. Gostam de continuar a sustentar que a cultura tradicional é a totalidade da cultura, como se a ordem natural não existisse. Como se a investigação da ordem natural não fosse interessante, nem enquanto valor autónomo nem pelas suas consequências. Como se a construção científica do mundo físico não fosse, na 
sua profundidade intelectual, na sua complexidade e articulação, a mais bela e prodigiosa obra colectiva do espírito do homem. E contudo a maior parte dos não cientistas não faz a mínima ideia do que seja essa construção. Ainda que a queiram compreender, não são capazes. Tudo se passa, em larga medida, como se, para uma extensão imensa da experiência intelectual, pertencessem a um grupo destituído de ouvido. Mas esta falta de ouvido não é um efeito da natureza, resulta da sua formação, ou antes, da sua falta de formação. (Snow, 1996, p. 79)

É logo a seguir que surge a famosíssima invectiva aos homens de letras a respeito da Segunda Lei da Termodinâmica, ou Lei da Entropia (ou melhor Lei da Não Diminuição a Entropia em sistemas isolados, sendo a entropia uma grandeza física que expressa o grau de desordem de um sistema), comparando-a à obra de William Shakespeare:

Como acontece a quem tem falta de ouvido, os não cientistas não sabem o que perdem. Soltam uma exclamação de dó ao ouvirem falar de cientista que nunca leram uma grande obra de literatura inglesa. Desprezam-nos, considerando-os especialistas ignorantes. Mas a sua própria ignorância e o seu próprio grau de especialização são também alarmantes. Estive muitas vezes em reuniões de pessoas que, pelos critérios da cultura tradicional, eram altamente instruídas e que expressavam com uma complacência notável a sua incredibilidade relativamente à ignorância dos cientistas. Numa ou duas ocasiões semelhantes, senti-me provocado e perguntei aos circunstantes quantos de entre eles saberiam dizer o que era a Segunda Lei da Termodinâmica. A resposta era fria: e negativa, também. Mas o que estava a perguntar equivalia, do ponto de vista científico, a esta outra pergunta: Leu alguma coisa de Shakespeare? Hoje penso que, mesmo que tivesse feito uma pergunta ainda mais simples - como, por exemplo: o que entende Você por massa, ou por aceleração? - que equivale, em termos científicos, à pergunta - Sabe ler? - só uma em cada dez dessas pessoas altamente instruídas compreenderia o meu inglês. É assim que, perante o grande edifício da física moderna, a maior parte das pessoas mais inteligentes do mundo ocidental demonstra uma compreensão que não ultrapassa a que seria acessível aos seus antepassados neolíticos. (Snow, 1996, pp. 79-80)

Como a questão é pertinente e o estilo de quem a coloca tem a vivacidade necessária para suscitar a atenção, não admira que tenha feito correr rios de tinta. Num texto que publicou quatro anos mais tarde, incluído em "As Duas Culturas em Retrospectiva", Snow (1996) recuou um pouco em relação à sua posição anterior com ênfase na separação das duas culturas, tendo falado da possibilidade de uma sua aproximação recíproca no que se poderia chamar uma "terceira cultura". Ao analisar a polémica provocada pelo seu escrito de 1959, fez, porém, notar que não estava sozinho e nem sequer 
era o primeiro a dizer o que tinha dito. Outros autores tinham apontado antes dele a questão de valorizar a ciência no quadro da cultura humana (o adjetivo "humana" não é pleonasmo, pois alguns autores falam de cultura no mundo animal, e.g., Mosterín, 2009). Em particular, referiu por várias vezes um seu contemporâneo, o matemático polaco-britânico, de origem judaica, Jacob Bronowski (1908-1974), que, tal como Snow, fez carreira na administração pública britânica e, também tal como ele, alcançou uma posição destacada no espaço público da discussão intelectual. Bronowski, talvez ainda em maior medida do que Snow, é um dos raros polímatos da modernidade: foi historiador de ciência (é autor de "A Tradição Intelectual do Ocidente", com Bruce Mazlich, saído nas Edições 70, em 2002), divulgador de ciência (é o autor de uma aclamada série de televisão, que passou na BBC, cujo guião está em forma de livro, "The Ascent of Man" (1973), do qual existe uma tradução brasileira, "A Escalada do Homem"), poeta, dramaturgo e crítico literário.

De facto, Bronowski publicou em 1959 na revista Universities Quaterly três artigos associados a três palestras por ele proferidas no Massachusetts Institute of Technology, em Boston, nos Estados Unidos, em 16 de Fevereiro, 5 e 19 de Março de 1953, que, no seu conjunto, constituem o ensaio "Science and Human Values" (1956), do qual saiu uma edição nas Publicações Dom Quixote em 1972 sob o título "Ciência e Valores Humanos", tendo surgido uma nova tradução duas décadas mais tarde, inserida numa coletânea intitulada "A responsabilidade do cientista e outros escritos" (1992), um volume com introdução, organização, notas e tradução de Nunes dos Santos, Auretta e Câmara Leme, docentes da Faculdade de Ciências e Tecnologia da Universidade Nova de Lisboa.

O leit-motiv de Bronowski - a unidade da cultura - foi ilustrado por ele, não com a obra do dramaturgo de Statford-upon-Avon, como aconteceu no ensaio de Snow, mas com uma definição do poeta e crítico romântico inglês Samuel Taylor Coleridge, que, em 1814, no seu livro "On The Principles of Genial Criticism Concerning the Fine Arts" (1971) escreveu: "A definição mais geral de Beleza, é portanto - posso cumprir a minha ameaça de me dirigir aos leitores com palavras duras - Diversidade na Unidade" (no original, Multeity in Unity). Bronowski, servindo-se do conceito de Coleridge, afirmou:

Quando Coleridge tenta definir a beleza, regressava sempre a um único pensamento profundo: a beleza, disse, é a "unidade na variedade". A ciência não é nada mais do que a procura da descoberta da unidade na desordenada variedade da natureza - ou, mais exactamente, na variedade da nossa experiência. A poesia, a pintura, as artes, são a mesma procura, na frase de Coleridge, da unidade na variedade. Cada um, à sua própria maneira, procura as semelhanças sob a variedade da experiência humana. O que vem a ser uma imagem poética senão a apreensão e a exploração de uma semelhança escondida, o manter juntas duas partes de uma comparação que vão dar mais profundidade uma à outra? (Bronowski, 1992, p. 120)

Se Snow, na sua polémica peça, valorizou a ciência que, na sua opinião, estava no espaço público insuficientemente apreciada em comparação com a arte, Bronowski, na 
mesma linha, chamou a atenção para a unidade essencial que existia entre ciência e arte: para ele não existiam duas culturas, mas uma só. O menosprezo pela ciência nalguns círculos não tinha, ao fim e ao cabo, justificação, resultando apenas de um preconceito, perpetuado porventura por um inerte sistema de educação. Mais adiante no mesmo ensaio escreveu Bronowski, em defesa da profunda unidade cultural que descortinava entre ciência e arte:

As descobertas da ciência, os trabalhos de arte, são explorações - ou antes, são explosões de uma semelhança oculta. O investigador científico ou o artista apresentam neles dois aspectos da natureza e funde-os num só. É o acto da criação que nasce um pensamento original, e o acto é o mesmo na ciência ou nas artes. (Bronowski, 1992, p. 124)

É curioso que, já num tempo pós-Snow, o matemático Bronowski tenha achado conveniente efetuar a apologia da poesia. Numa entrevista que deu ao norte-americano George Derfer, um académico especializado em filosofia da religião, publicada num número da revista "The American Scholar" (1974) e republicada, em tradução portuguesa, no volume coordenado por Nunes dos Santos e outros no capítulo "A Ciência, a Poesia e a 'Especificidade Humana' " Bronowski (1992) responde assim a uma das perguntas: "A poesia é um tema maravilhoso que deveríamos considerar sempre que falamos de ideias científicas, porque nos relembra que se pode comunicar uma verdade de indubitável valor intelectual sem necessidade de ser complementada por qualquer sistema de equações" (Bronowski, 1992, p. 187).

A diferença entre ciência e arte seria, portanto, mais de linguagem do que de conteúdo. Se a linguagem da ciência era a matemática (como já se sabia desde que o italiano Galileu Galilei tinha escrito em “Il Saggiatori” (1623, p. 238 da tradução inglesa), que "[o Livro da Natureza] está escrito na linguagem da matemática e os seus caracteres são triângulos, círculos e outras figuras geométricas" a poesia exprimia-se através da palavra, numa linguagem mais plástica do que a da matemática mas mesmo assim não isenta de regras.

Mas, se ciência e arte se encontram conluiadas no projeto de apreensão da unidade do mundo, permanecendo apenas separadas pelo uso de linguagens diferentes, uma aparentemente mais inteligível por se dirigir em primeira linha à sensibilidade, será que haveria algum paralelismo no que respeita à metodologia? Bronowski, na mesma entrevista (1992), defendeu que tanto a poesia como a ciência dependem da capacidade humana de imaginar, isto é, "da "nossa capacidade de reter imagens na mente, de identificar estas imagens com elementos constitutivos da realidade, e de reorganizar estes elementos em situações imaginárias." E acrescentou, para que não restassem quaisquer dúvidas sobre a conclusão que quer transmitir (Bronowski, 1992): "Todas as nossas actividades intelectuais dependem desta projecção tanto na ciência como na poesia".

De facto, a imaginação é a grande arma tanto da ciência como da arte (Fiolhais, 2008). O físico suíço e norte-americano nascido na Alemanha Albert Einstein, quando em 1929 um jornalista lhe pediu para escolher, entre o conhecimento e a imaginação, 
qual era para ele mais fiável, respondeu sem hesitar: "A imaginação é mais importante do que o conhecimento. O conhecimento é limitado. Mas a imaginação dá a volta ao mundo" (Calaprice, 2011, p. 12).

Um amigo de Einstein recordaria postumamente uma frase com o mesmo sentido que ouviu dele: "Quando faço uma auto-análise e olho para os meus métodos de pensar, chego à conclusão que o dom da imaginação teve para mim maior significado do que o meu talento para absorver o conhecimento em si" (Calaprice, 2011, p. 26).

Neste quadro, gostaria de citar um autor pouco conhecido, o matemático e engenheiro geógrafo António Lobo Vilela (1902-1966), e uma obra dele, "Ciência e Poesia" (Vilela, 1955; 2012), sobre as relações entre ciência e arte. Poder-se-á pensar que as posições nos anos 50 do século passado, primeiro de Bronowski e depois de Snow, em defesa da unidade da cultura humana pouco eco encontraram no limitado meio cultural português do tempo do Estado Novo, dominado por António de Oliveira Salazar. De facto, só apareceram muito mais tarde na língua portuguesa, pela mão do Dom Quixote, ficando o seu conhceimento restrito às muito poucas pessoas que acompanhavam a discussão cultural na Europa do pós-guerra. Mas, curiosamente, Lobo Vilela, também matemático como Bronowski e opositor ao Estado Novo (Vilela, 1999), numa conferência no Museu de João de Deus, em Lisboa, no dia 22 de Junho de 1955, escassos dois anos após a palestra de Bronowski e quatro anos antes da de Snow, enfatizou, sem citar Bronowski, a proximidade entre ciência e poesia. O livro que transcreve a conferência intitulado "Ciência e Poesia" (Vilela, 1955; 2012) e publicado pela Portugália Editora no ano em que foi proferida, começa assim: "Radicou-se há muito no meu espírito a convicção de que entre sábios e poetas existem íntimas afinidades, contrariamente a uma opinião muito vulgarizada" (s/p).

Lembrou, a este propósito, os célebres versos do poeta Fernando Pessoa (18881935), ou melhor, de Álvaro de Campos, sobre a equivalência estética entre o binómio de Newton e a Vénus de Milo, que data de ca. 1915 (Pizarro \& Cardiello, 2014): "O binómio de Newton é tão belo como a Vénus de Milo. / O que há é pouca gente para dar por isso."

E, recuando mais atrás, cita o poeta, escritor, jornalista e político Guerra Junqueiro (1850-1923), no seu prefácio à segunda edição do seu livro de poesia Morte de D. João, saído originalmente em 1874:

A poesia é a verdade transformada em sentimento. A lei descoberta por Newton tanto pode ser explicada num livro de física, como cantada num livro de versos. O sábio analisa-a, demonstra-a, e o poeta, partindo dessa demonstração, tira dos factos todas as consequências morais, sociais e religiosas, traduzindo-as numa forma sentimental. A ciência, neste caso, dá o convencimento, a certeza; a poesia dá a emoção, o entusiasmo. (Junqueiro, 1887, p. 10)

E também cita logo a seguir o poeta e escritor Antero de Quental (1842-1891), contemporâneo de Junqueiro, transcrevendo um excerto da carta que escreveu, ainda no seu tempo de Coimbra, ao economista Anselmo de Andrade: 
O chão, sobre que assenta a certeza de hoje, formou-se pelos aluviões sucessivos da intuição antiga. O que é ciência foi já poesia: o sábio foi já cantor, o legislador poeta; e a evidência, uma adivinhação, um admirável palpite, cujas profundas conclusões são ainda o espanto e porventura o desespero das mais rigorosas filosofias. E, se nadamos hoje em plena luz de razão, foi entretanto a poesia, foi essa doce mão, que nos guiou por entre o pálido crepúsculo dos velhos sonhos. Velhos? Não: sonhos eternos! (Quental, 1989, p. 32)

Sendo notório o isolamento português nos anos 50 do século $X X$, afigura-se notável que, na mesma altura em que Bronowski e Snow colocavam na agenda cultural a questão da unidade da cultura, um pensador nacional tivesse discorrido sobre o mesmo tema, ademais citando autores nacionais (Pessoa, Junqueiro e Quental em vez de Shakespeare ou Coleridge). No Portugal de Salazar o terreno estava seco para o diálogo cultural - Lobo Vilela era apenas um dos vários intelectuais banidos pelo regime, impedido como estava de exercer a sua actividade de professor no ensino secundário e, por isso, obrigado a viver de traduções e explicações - mas bem poderia ter sido irrigado por haver pessoas que conheciam as boas fontes do século XIX. O livro de Lobo Vilela encontrou leitores perspicazes: um deles foi o grande matemático José Sebastião e Silva, que o cita num dos livros em que apresenta a sua reforma do ensino secundário da Matemática (Silva, 1977) e outro o físico e historiador de ciência Luís Miguel Bernardo, que o refere na sua recente história da cultura científica em Portugal (Bernardo, 2013).

Como evoluiu entretanto a questão da unidade da cultura no mundo e em Portugal? Nos anos 80 e 90, com o início que podemos remontar à série televisiva e ao livro que a acompanhou "Cosmos", de Carl Sagan (2009), uma série de televisão que foi uma digna sucessora da "Escalada do Homem", de Bronowski, numa altura em que se registou uma vaga da ciência no espaço mediático. O discurso científico passou a estar na moda. Emergiram, além do inigualável Sagan, outros grandes divulgadores de ciência como os físicos Roger Penrose e Murray GellMann (um britânico e outro norte-americano), os biólogos Richard Dawkins e Stephen Jay Gould (idem) e o psicólogo Steven Pinker (norte-americano). Em 1995 surgiu um livro, intitulado "Terceira Cultura" (1997), do agente literário norte-americano John Brockman, criador da revista digital Edge. Nesse livro e na linha de Snow no ensaio de revisitação de "As Duas Culturas", Brockman fala de uma "terceira cultura" na qual pretendia conciliar as culturas científica e literária. Mas, para Brockman, nestes novos tempos, não havia dúvidas sobre a primazia da cultura científica: os novos intelectuais públicos eram os cientistas, nomeadamente aqueles com maior capacidade para divulgar a ciência junto das massas. O livro de Brockman dava voz a toda uma pleiade de divulgadores que incluía os referidos nomes.

A história das ideias é feita de fluxos e refluxos. É bem sabido que as correntes pós-modernas, que convencionalmente entraram na filosofia em 1979 com o ensaio "A Condição Pós-Moderna: Um Relatório sobre o Conhecimento" (2003) do filósofo francês Lyotard vieram relativizar o projeto da ciência. Lyotard, cuja intenção original era discutir 
a influência da tecnologia, criticou o anseio de construção da metanarrativa subjacente ao Iluminismo, preferindo uma diversidade de pequenas narrativas, como aquelas que a linguagem literária proporciona. Se a linguagem da matemática é universal, tendo como fito a eliminação da ambiguidade, já a linguagem da poesia se alimentava da polissemia. O famoso caso Sokal (Sokal \& Bricmont, 1999), que ocorreu em 1996 quando o físico-matemático norte-americano Alan Sokal publicou um artigo, polvilhado de jargão científico mas que não passava de um embuste, na "Social Text" (1996), uma revista de renome de ciências sociais, porta-voz pós-modernismo. Os avaliadores terão pensado que as ciências sociais ganhariam legitimidade especial pelo uso da linguagem da ciência. Contudo, no caso em causa, o discurso era perfeitamente vazio de sentido científico e os admiradores do som poético estavam simplesmente a elogiar o absurdo. $A$ discussão que se seguiu à publicação do texto de Sokal, na qual não poderiam deixar de transparecer alguma desconfiança e ressentimento, não ajudou à unidade das ciências e também não ajudou à construção de pontes entre ciências e artes. Gould, no seu ensaio "The Hedgehog, the Fox, and the Magister's Pox" (2003), contestou que os cientistas estivessem envolvidos numa "guerra das ciências" pois a maioria até a desconheceria. O diálogo entre ciências e artes, não isento de dificuldades, prossegue nos dias de hoje. Outro biólogo norte-americano, Wilson, fala de "consiliência" (1999), um grande encontro entre vários ramos da ciência, incluindo as ciências humanas, que seria como uma ponto ómega do empreendimento de busca do conhecimento.

Em Portugal passos de aproximação entre ciência e poesia são visíveis pela publicação recente de duas antologias sobre poemas de tema científico, uma mais aparatosa, organizado por Graça Moura e Maria Bochicchio, "O Binómio de Newton e a Vénus de Milo. Poesia e Ciência na Literatura Portuguesa" (2011) (o título alude ao poema de Álvaro de Campos)], e outra mais modesta, organizado por Malhó, "O Bosão do João" (2014). Também no domínio das artes visuais e das artes performativas, acompanhando movimentos mundiais, têm surgido entre nós várias tentativas de aproximação entre as "duas culturas".

Para terminar, permito-me deixar a minha opinião de concordância com Bronowski, indo para além do que deixei escrito sobre a ciência e a arte (1994, 2007, 2008, 2013, 2015). Penso que falar de três culturas é complicar ainda mais uma questão já de si complexa, que carece de simplificação e não de complexificação. Não temos que abandonar nem a cultura artística nem a cultura científica, que cresceram separadas mas com contactos assíduos que conduziram sempre a enriquecimento mútuo, para adotar uma terceira. Temos é que encontrar pontes permanentes entre as duas, de modo a que fique progressivamente evidente tratar-se de uma só.

O físico austríaco Erwin Schroedinger chamou a atenção, em conferências que fez em Londres em 1948 e em Dublin em 1950, reunidas na coletânea "A Natureza, os Gregos e Ciência e Humanismo" (1999), que as ciências se destinam todas a satisfazer a necessidade humana de auto-conhecimento, como afinal as artes. Para ele, a inquietação última do homem foi e será "quem somos nós?" (Schroedinger, 1999), refletida na inscrição no Templo de Delfos "Conhece-te a ti mesmo". O homem da arte e o homem 
da ciência são, afinal, um e o mesmo homem. Só há uma cultura, a cultura humana, que tem várias facetas, essas duas e ainda outras, como por exemplo a faceta religiosa. A ideia de que a ciência está fora da cultura parece-me não só falsa como perniciosa: a ciência - a capacidade humana de responder, com base num certo método, a questões a respeito da Natureza - é uma das maiores conquistas do espírito humano.

Talvez o melhor título para uma abordagem das duas culturas seja a de uma série de romances de C. P. Snow: "Strangers but brothers" (1940). A cultura literária e a científica poderão parecer estranhas uma à outra, mas são inequivocamente irmãs.

\section{REFERÊNCIAS BIBLIOGRÁFICAS}

Bernardo, L. M. (2013). História da cultura científica em Portugal. Porto: Editora da Universidade do Porto.

Brockman, J. (1997). A terceira cultura. Lisboa: Círculo de Leitores.

Bronowski, J. (1956). Science and human values. Nova Iorque: Julian Messner.

Bronowski, J. (1972). Ciência e valores humanos. Lisboa: Publicações D. Quixote.

Bronowski, J. (1979). A escalada do homem. São Paulo: Martins Fontes.

Bronowski, J. (1992). A responsabilidade do cientista e outros escritos. Lisboa: Publicações Dom Quixote.

Bronowski, J. \& Mazlich, B. (2002). A tradição intelectual do Ocidente. Lisboa: Edições 70.

Calaprice, A. (Ed.). (2011). The ultimate quotable Einstein. Princeton: The Princeton University Press.

Coleridge, S. T. (1971). On the principles of genial criticism concerning the fine arts. In E. H. Adams (Ed.), Critical Theory Since Plato (pp. 471-476). New York: Harcourt Brace Jovanovich.

Derfer, G. (1974). Science, poetry and "human specificity", an interview with J. Bronowski. The American Scholar, 43, 386-404.

Fiolhais, C. (1994). Universo, computadores e tudo o resto. Lisboa: Gradiva.

Fiolhais, C. (2007). O espaço e a alma, poemas escolhidos. Prefácio a F. Xavier Malcata. Porto: Corpos. Retirado de http://dererummundi.blogspot.com/2007/06/o-princpio-da-incerteza.html.

Fiolhais, C. (2008). Imaginação, ciência e arte. Biblos, 4, 2. ${ }^{a}$ série, 3-16.

Fiolhais, C. (2013). Einstein: entre ciência e arte. In J. Carvalho (Ed.), Arte e Ciências em Diálogo (pp. 27-35). Coimbra: Grácio Editor.

Fiolhais, C. (2015). Ciência e humanismo. A visão da ciência de Erwin Schrödinger, Biblos, 1(3), 127-151.

Galileu Galilei. (1623). Il sagiatore. Retirado de http://www.princeton.edu/ hos/h291/assayer.htm.

Gould, S.J. (2003). The hedgehog, the fox, and the magister's pox. New York: Harmony Books.

Graça Moura, V. \& Bochicchio, M. (Eds.) (2011). O binómio de Newton a A Vénus de Milo. Poesia e ciência na literatura portuguesa. Lisboa: Aletheia.

Junqueiro, G. (1887). A morte de D. João. Lisboa: Livraria António Maria Pereira. 
Lyotard, J.F. (2003). A condição pós-moderna: um relatório sobre o conhecimento. Lisboa: Gradiva.

Malhó, R. (Ed.) (2014). O Bosão do João. 88 poemas com ciência. Lisboa: By the Book.

Mosterín, J. (2009). La cultura humana. Madrid: Espasa-Calpe.

Pizarro, J. \& Cardiello, A. (Eds.) (2014). Obra completa de Álvaro de Campos. Lisboa: Tinta da China.

Quental, A. (1989). O sentimento da imortalidade (Carta ao Sr. Anselmo de A.). In Obras Completas de Antero de Quental, Filosofia. Lisboa: Editorial Comunicação.

Sagan, C. (2009). Cosmos. Lisboa: Gradiva.

Schrödinger, E. (1999). A natureza e os gregos e ciência e humanismo. Lisboa: Edições 70.

Silva, J.S. (1977). Guia para a utilização do compêndio de matemática, (2..$^{\circ}$ e $3{ }^{\circ}$ vols.). Lisboa: Edições GEP. Retirado de http://issuu.com/casadasciencias/docs/ guia_para_a_utilizacao_do_compendio_1db868137a2efb.

Snow, C. P. (1940). Strangers but brothers. London: Faber and Faber.

Snow, C. P. (1963). The two cultures and a second look. Cambridge: Cambridge University Press.

Snow, C. P. (1965). As duas culturas. Lisboa: Publicações Dom Quixote.

Snow, C. P. (1996). As duas culturas. Lisboa: Presença.

Sokal, A. (1996). Transgressing the boundaries: Towards a transformative hermeneutics of quantum gravity. Social Text, 46/47, 217-252.

Sokal, A. \& Bricmont, J. (1999). Imposturas intelectuais. Lisboa. Gradiva.

Vilela, A. C. L. (2009). Vilela e a polémica sobre a universidade e o ensino nos inícios do Estado Novo. Lisboa: Fundação Calouste Gulbenkian.

Vilela, A. L. (2012). Ciência e poesia. Lisboa: Portugália.

Wilson, E. O. (1999). Consiliência, a unidade do conhecimento. Rio de Janeiro: Campus.

\section{NOTA BIOGRÁFICA}

Carlos Fiolhais é Professor no Departamento de Física e investigador no Centro de Física da Universidade de Coimbra.

E-mail: tcarlos@uc.pt

Universidade de Coimbra, Departamento de Física, Rua Larga, 3004-516 Coimbra.

* Submetido: 17-12-2015

* Aceite: 21-12-2015 